\title{
In Vitro Suppression of Serum Elastase-Inhibitory Capacity by Reactive Oxygen Species Generated by Phagocytosing Polymorphonuclear Leukocytes
}

\author{
HARVey CARP and AARON JANOFF, Department of Pathology, Health Sciences Center, \\ State University of New York at Stony Brook, Stony Brook, New York 11794
}

A B S T R A C T Human polymorphonuclear leukocytes (PMN) phagocytosing opsonized antigen-antibody complexes, produce dialyzable species of activated oxygen which are capable of partially suppressing the elastase-inhibiting capacity (EIC) of whole human serum or purified human $\alpha_{1}$-proteinase inhibitor. Serum EIC was partially protected by superoxide dismutase, catalase, or mannitol, suggesting that hydroxyl radical, formed by interaction of superoxide radical and hydrogen peroxide, might be responsible for this effect. $\mathrm{NaN}_{3}$ also partly protected EIC, implicating myeloperoxidase-mediated reactions as well. An artificial superoxide radical-generating system, involving xanthine and xanthine-oxidase, could be substituted for phagocytosing PMN with resultant EIC suppression. These results are consistent with previous demonstrations of the release of potent oxidants by stimulated PMN, as well as earlier studies from our laboratory showing sensitivity of $\alpha_{1}$-proteinase inhibitor to inactivation by oxidants. Oxidative inactivation of proteinase inhibitors in the microenvironment of PMN accumulating at sites of inflammation may allow proteases released from these cells to more readily damage adjacent connective tissue structures.

\section{INTRODUCTION}

Human leukocytes contain potentially injurious substances within their cytoplasmic granules, including

Received for publication 5 January 1979 and in revised form 29 January 1979. proteases capable of degrading connective tissue structures and basement membrane (1). These proteases include human polymorphonuclear leukocyte $(\mathrm{PMN})^{1}$ elastase (2) and collagenase (3). It has been shown that PMN accumulation at sites of inflammation, including sites of immune complex deposition, may result in the escape of these enzymes to the outside of the cell with subsequent damage to surrounding tissue structures (4). A system of antiproteases is present in the circulation and tissue fluids which functions to inactivate proteases released from inflammatory cells (5). $\alpha_{1}$-proteinase inhibitor $\left(\alpha_{1}-\mathrm{Pi}\right)$ is an important component of this antiprotease system and is capable of inhibiting both PMN elastase and collagenase (5). It is believed that the local balance between released protease and tissue antiprotease plays a key role in determining whether damage will occur to connective tissues as a result of inflammation (5).

A recent report has shown that $\alpha_{1}-\mathrm{Pi}$ can be inactivated by exposure to several model free-radical oxidants as well as to oxidants present in cigarette smoke (6). Since leukocytes produce and release several reactive oxygen species during phagocytosis (7), the local balance between protease and antiproteases may be further disrupted during inflammation by the oxidative inactivation

${ }^{1}$ Abbreviations used in this paper: $\alpha_{1}-\mathrm{Pi}, \alpha_{1}$-proteinase inhibitor; EIC, elastase-inhibitory capacity; $\mathrm{H}_{2} \mathrm{O}_{2}$, hydrogen peroxide; HBSS, Hanks' balanced salt solution; HBSSG, HBSS containing $0.2 \%$ glucose; $\mathrm{HI}$, heat-inactivated; $\mathrm{O}_{2}{ }^{-}$, superoxide radical; $\cdot \mathrm{OH}$, hydroxyl radical; $\mathrm{PMN}$, polymorphonuclear leukocyte(s); SOD, superoxide dismutase. 
of $\alpha_{1}-\mathrm{Pi}$ in the microenvironment of PMN. In this event, tissue components adjacent to PMN at sites of inflammation would be even more susceptible to damage by proteases simultaneously released from these cells.

We tested this possibility in an in vitro system. The present report demonstrates that human PMN stimulated by exposure to opsonized antigen-antibody complexes release dialyzable oxidant species which in turn are capable of inactivating $\alpha_{1}-\mathrm{Pi}$. Indirect evidence is also presented to show that pathways dependent on superoxide radical $\mathrm{O}_{2}{ }^{-}$, hydrogen peroxide $\left(\mathrm{H}_{2} \mathrm{O}_{2}\right)$, and myeloperoxidase are involved in the inactivation of $\alpha_{1}-\mathrm{Pi}$.

\section{METHODS}

Preparation of PMN. Leukocyte suspensions containing $\cong 90 \%$ PMN were prepared from fresh, anticoagulated, normal human blood by dextran sedimentation as previously described (8). The cells were suspended in Hanks' balanced salt solution (HBSS), pH 7.8, containing $0.2 \%$ glucose (HBSSG) to give a final concentration of $4 \times 10^{6} \mathrm{PMN} / \mathrm{ml}$. Over $95 \%$ of the PMN excluded trypan blue, before and after the experimental period. Fresh serum, as a source of complement from the same individual, was simultaneously obtained.

Preparation of "pretreated" dialysis bags. Pretreated dialysis bags were prepared by incubating saline-filled dialysis tubing (type 8-667A, Fisher Scientific Co., Pittsburgh, Pa.) in $10 \%$ (wt/vol) bovine serum albumin for $48 \mathrm{~h}$ at $4^{\circ} \mathrm{C}$, to adsorb bovine serum albumin to the outer surface of the bag. The sealed bags were then washed with saline and incubated in $10 \%(\mathrm{vol} / \mathrm{vol})$ rabbit anti-bovine serum albumin antiserum (Miles Laboratories Inc., Elkhart, Ind.), diluted in saline, for $1 \mathrm{~h}$ at $22^{\circ} \mathrm{C}$. The bags were again washed with saline and then incubated in $10 \%$ (vol/vol) fresh human serum, diluted in saline, for $1 \mathrm{~h}\left(22^{\circ} \mathrm{C}\right)$. The bags containing opsonized antigen-antibody complexes on their outer surface, were then opened and washed with saline over both inner and outer surfaces and were cut into standard lengths, such that $1,600 \mathrm{~mm}^{2}$ would be exposed to the dialyzing solution in subsequent experiments. Control tubings containing no immune complex “coating" or containing antigen alone (bovine serum albumin) were also prepared.

Source of elastase inhibitor. Dilutions of a standard human serum containing $2.2 \mathrm{mg} / \mathrm{ml} \alpha_{1}-\mathrm{Pi}$ (determined by radial immunodiffusion) or of purified $\alpha_{1}-\mathrm{Pi}$ (a gift of Dr. J. C. Taylor, Scripps Clinic, La Jolla, Calif.) were used as a source of elastase inhibitor.

Assay of elastase inhibitory capacity. $\quad 50 \mu \mathrm{l}$ of a solution to be tested for elastase-inhibitory capacity (EIC) was incubated with $100 \mu \mathrm{l}$ of $0.06 \mu \mathrm{g} / \mu \mathrm{l}$ porcine pancreatic elastase (Elastin Products Co., St. Louis, Mo.) for $30 \mathrm{~min}$ at $37^{\circ} \mathrm{C}$, after which elastolytic activity was measured using elastin agarose plates as previously described (6). The molar ratio of active $\alpha_{1}-\mathrm{Pi}$ in the test solution to active elastase was 1 , when either $2.5 \%$ ( $\mathrm{vol} / \mathrm{vol}$ ) standard serum or $0.075 \mu \mathrm{g} / \mu \mathrm{l}$ purified $\alpha_{1}$-Pi was used.

Special reagents and assays. $\mathrm{O}_{2}^{-}$- was measured by a modification of the method of McCord and Fridovich (9), in which superoxide dismutase-sensitive reduction of cytochrome $c$ is followed spectrophotometrically at $550 \mathrm{~nm}$. In assaying $\mathrm{O}_{2}$ concentrations within the dialysis bags, cytochrome $c$ was present inside the tubing throughout the incubation interval to trap all $\mathrm{O}_{2}{ }^{-}$which diffused into the dialysand. Superoxide dismutase (SOD), (type 1, Sigma Chemical Co., St. Louis, Mo.) was also assayed according to McCord and Fridovich (9). Heat- inactivated SOD (HISOD) was prepared by autoclaving for $20 \mathrm{~min}$ at $120^{\circ} \mathrm{C}$. Both native and HISOD were diluted in $2 \mathrm{mM} \mathrm{Na}_{2}$ EDTA and then dialyzed against buffer before use to remove free metals. Catalase (C-40, Sigma Chemical Co.) was assayed according to Beers and Sizer (10) and was freed from contaminating SOD beforehand by repeated washings through XM100A diaflo ultrafiltration membrane (Amicon Corp., Scientific Systems Div., Lexington, Mass.). Heatinactivated catalase (HI catalase) was prepared by autoclaving for $20 \mathrm{~min}$ at $120^{\circ} \mathrm{C}$. Our preparations of SOD and catalase were checked and found to be free of cross-contamination. Xanthine oxidase was obtained from Boehringer Mannheim Biochemicals (Indianapolis, Ind.) as a partially purified preparation suspended in ammonium sulphate.

\section{RESULTS AND DISCUSSION}

Inactivation of elastase inhibitor by the xanthinexanthine oxidase reaction. Before using PMN to test for $\alpha_{1}$-Pi inactivation by $\mathrm{O}_{2}{ }^{-}$generated during phagocytosis, a model enzymatic $\mathrm{O}_{2}{ }^{-}$-generating system was employed using the xanthine-xanthine oxidase reaction. When xanthine oxidase converts xanthine to uric acid, a reproducible flux of $\mathrm{O}_{2}{ }^{-}$is produced (9). Hydrogen peroxide $\left(\mathrm{H}_{2} \mathrm{O}_{2}\right)$ is also generated by this system, since $\mathrm{H}_{2} \mathrm{O}_{2}$ production always accompanies $\mathrm{O}_{2}{ }^{-}$production as a result of spontaneous or enzymatic dismutation of $\mathrm{O}_{2}{ }^{-}(9)$. In addition, $\mathrm{H}_{2} \mathrm{O}_{2}$ and $\mathrm{O}_{2}{ }^{\circ}$, in the presence of trace metal catalysts normally present in biological fluids, have been shown to generate an even more potent oxidant, hydroxyl radical $(\cdot \mathrm{OH})(11)$. Table I summarizes all experiments employing the xanthinexanthine oxidase system. In these experiments, the enzymatic reagents were present in $4.0 \mathrm{ml}$ of external solution ("dialysate" in Table I), whereas $\alpha_{1}-\mathrm{Pi}$ or serum were enclosed within dialysis bags containing $750 \mu \mathrm{l}$ of solution and incubating in the external bath ("dialysand" in Table I). Incubation was for $25 \mathrm{~min}$ at $37^{\circ} \mathrm{C}$ in a gyrorotary water bath. At the end of this interval, both EIC and $\mathrm{O}_{2}{ }^{\circ}$ content of the dialysand were measured as described in Methods.

As shown in Table I, the xanthine-xanthine oxidase “activated oxygen"-generating system was capable of partially suppressing EIC of both serum and purified $\alpha_{1}-\mathrm{Pi}$. The xanthine oxidase system had no effect on activity of elastase alone (Table I). Separate experiments showed that dialysis tubings exposed for $\mathrm{l} \mathrm{h}$ to the oxidizing radicals did not become "leaky", so that loss of antiproteases from the bag was not responsible for these results.

SOD, an enzyme that specifically catalyzes the dismutation of $\mathrm{O}_{2}{ }^{\circ}$ into $\mathrm{H}_{2} \mathrm{O}_{2}$ and oxygen (9), was able to protect serum against inactivation by xanthine oxidase (Table I). This implies that $\mathrm{O}_{2}{ }^{\circ}$ must be present for inactivation to occur. Catalase, which decreases available $\mathrm{H}_{2} \mathrm{O}_{2}(10)$, also protected serum inhibitors (Table $\mathrm{I}$ ). This implies that $\mathrm{H}_{2} \mathrm{O}_{2}$ must also be present for these inhibitors to be inactivated. HISOD and HI catalase were without effect (Table I). The fully protective ef- 
TABLE I

Inactivation of Purified $\alpha_{1}-$ Pi and Serum EIC by Xanthine-Xanthine Oxidase

\begin{tabular}{|c|c|c|c|c|c|c|}
\hline \multicolumn{2}{|c|}{ Dialysate contents* } & \multicolumn{3}{|c|}{ Dialysand contents $₫$} & \multicolumn{2}{|c|}{ Assay results } \\
\hline Xanthine & $\begin{array}{l}\text { Xanthine } \\
\text { oxidase }\end{array}$ & Serum & $\alpha_{1}-\mathrm{Pi}$ & $\begin{array}{l}\text { Protective } \\
\text { agent }\end{array}$ & $\begin{array}{c}\mathrm{O}_{2}: \text { in } \\
\text { dialysand } \S\end{array}$ & $\begin{array}{c}\text { EIC of } \\
\text { dialysand" }\end{array}$ \\
\hline & & & & & \multicolumn{2}{|c|}{$\%$} \\
\hline- & - & - & - & - & 0 & 0 \\
\hline- & - & + & - & - & 0 & 100 \\
\hline+ & - & + & - & - & 0 & $100 \pm 3.0$ \\
\hline- & + & + & - & - & 0 & $99 \pm 2.4$ \\
\hline+ & + & + & - & - & 100 & $63 \pm 1.6$ \\
\hline+ & + & + & - & SOD & 0 & $102 \pm 2.4$ \\
\hline+ & + & + & - & Catalase & $98 \pm 2.3$ & $103 \pm 2.1$ \\
\hline+ & + & + & - & Mannitol & $97 \pm 2.1$ & $97 \pm 3.5$ \\
\hline+ & + & + & - & HISOD & $100 \pm 1.5$ & $62 \pm 1.5$ \\
\hline+ & + & + & - & HI catalase & $102 \pm 3.1$ & $64 \pm 3.1$ \\
\hline+ & + & - & - & - & NT & $0^{4}$ \\
\hline+ & + & - & - & SOD & NT & $0^{\pi}$ \\
\hline+ & + & - & - & Catalase & NT & $0^{\top}$ \\
\hline+ & + & - & - & Mannitol & NT & $0^{\pi}$ \\
\hline- & - & - & + & - & NT & 100 \\
\hline+ & + & - & + & - & NT & $44 \pm 2.1$ \\
\hline
\end{tabular}

NT, not tested.

* Concentrations: xanthine, $50 \mu \mathrm{M}$; xanthine oxidase, $0.6 \mu \mathrm{M}$. The buffer was HBSS, pH 7.8.

† Concentrations: SOD and HISOD, $280 \mathrm{U} / \mathrm{ml}$; catalase and HI catalase, $50 \mathrm{U} / \mathrm{ml}$; mannitol, $20 \mathrm{mM}$; pure $\alpha_{1}-\mathrm{Pi}, 0.075 \mu \mathrm{g} / \mu \mathrm{l}$; human serum, $2.5 \%$ ( $\mathrm{vol} / \mathrm{vol}$ ). The buffer was HBSS, $\mathrm{pH} 7.8$.

$\S$ The results (mean of three experiments \pm 1 SEM) are expressed as a percentage of $\mathrm{O}_{2}:$ detected under standard conditions (only xanthine and xanthine oxidase in the dialysate). $100 \%$ corresponds to $3.4 \mathrm{nM}$ of $\mathrm{O}_{2}{ }^{\circ}$.

"The results (mean of three experiments \pm 1 SEM) are expressed as a percentage of EIC of serum or pure $\alpha_{1}-\mathrm{Pi}$ not exposed to xanthine-xanthine oxidase reaction. EIC $=$ elastase standard - elastase + serum $\left(\right.$ or $\left.\alpha_{1}-\mathrm{Pi}\right) /$ elastase standard $\times 100$.

"Controls for effects of all reagents used on the enzymatic activity of elastase (EIC $=0$ represents $100 \%$ elastolysis $)$.

fects of either catalase or SOD suggest that neither $\mathrm{H}_{2} \mathrm{O}_{2}$ nor $\mathrm{O}_{2}{ }^{-}$alone are capable of inactivating serum, but that a product of the two may be responsible. This is supported by the observation that $50 \mathrm{mM} \mathrm{H}_{2} \mathrm{O}_{2}$, an amount far in excess of that generated by our xanthine oxidase system, does not inactivate pure $\alpha_{1}-\mathrm{Pi}$ (data not shown). $\cdot \mathrm{OH}$ and similar reactive species whose generation is dependent on $\mathrm{H}_{2} \mathrm{O}_{2}$ and $\mathrm{O}_{2}{ }^{-}$can be neutralized by mannitol, a free radical scavenger capable of reacting with $\cdot \mathrm{OH}$ but unreactive towards $\mathrm{H}_{2} \mathrm{O}_{2}$ or $\mathrm{O}_{2} \cdot$ (12). As shown in Table I mannitol protected serum elastase inhibitors against inactivation by the xanthine oxidase system.

Taken together, the results in Table I suggest that $\mathrm{H}_{2} \mathrm{O}_{2}$ and $\mathrm{O}_{2}{ }^{-}$, through generation of a more potent oxidant (perhaps $\cdot \mathrm{OH}$ ), are capable of suppressing the EIC of serum, probably by oxidatively inactivating $\alpha_{1}-\mathrm{Pi}(6)$.
Inactivation of elastase inhibitor by phagocytosing $P M N$. One in vitro model of immunologic injury uses opsonized immune complexes fixed to a nonphagocytosable surface such as a micropore filter to simulate in vivo immune complex deposition (4). PMN adhere to the surface and are stimulated to release their tissue-damaging lysosomal contents to the outside of the cell (4). Under similar conditions, PMN are also stimulated to produce and release a number of oxygen related reactive species, thought to include $\mathrm{O}_{2}{ }^{\circ}, \mathrm{H}_{2} \mathrm{O}_{2}$, singlet oxygen, $\cdot \mathrm{OH}$ and other molecules with similar reactivities (7). The experiments summarized in Table II were performed using opsonized antigen-antibody complexes fixed to the nonphagocytosable outer surface of a dialysis bag as a stimulus for release of reactive oxygen species by human PMN. Under these conditions, $\cong 6 \times 10^{6} \mathrm{PMN}$ adhered to the $1,600-\mathrm{mm}^{2}$ outer surface of the pretreated dialysis tubing and, after $60 \mathrm{~min}$ 
TABLE II

Inactivation of Purified $\alpha_{1}-P i$ and Serum EIC by Phagocytosing PMN

\begin{tabular}{|c|c|c|c|c|c|c|c|}
\hline \multirow{2}{*}{$\begin{array}{c}\text { Dialysat } \\
\begin{array}{c}\text { Pretreated } \\
\text { dialysis tubing } \\
\text { (see text) }\end{array}\end{array}$} & \multirow[b]{2}{*}{ PMN } & \multirow[b]{2}{*}{$\mathrm{NaN}_{3}$} & \multicolumn{3}{|c|}{ Dialysand contentst } & \multicolumn{2}{|c|}{ Assay results } \\
\hline & & & Serum & $\alpha_{1}-\mathrm{Pi}$ & $\begin{array}{c}\text { Protective } \\
\text { agent }\end{array}$ & $\begin{array}{c}\mathrm{O}_{2}{ }_{2} \text { in } \\
\text { dialysand } \S\end{array}$ & $\begin{array}{c}\text { EIC of } \\
\text { dialysand" }\end{array}$ \\
\hline & & & & & & \multicolumn{2}{|c|}{$\%$} \\
\hline+ & - & - & - & - & - & () & () \\
\hline+ & - & - & + & - & - & 0 & 100 \\
\hline+ & + & - & + & - & - & 100 & $64 \pm 2.3$ \\
\hline - & + & - & + & - & - & 0 & $100 \pm 3.1$ \\
\hline+ & + & - & + & - & SOD & 0 & $81 \pm 1.9$ \\
\hline+ & + & - & + & - & Catalase & $97 \pm 2.3$ & $84 \pm 2.0$ \\
\hline+ & + & - & + & - & Mannitol & $98 \pm 2.9$ & $83 \pm 1.9$ \\
\hline \multirow[t]{2}{*}{+} & + & - & + & - & SOD + catalase & & \\
\hline & & & & & + mannitol & 0 & $81 \pm 1.8$ \\
\hline+ & + & - & + & - & HISOD & $97 \pm 3.5$ & $60 \pm 2.4$ \\
\hline+ & + & - & + & - & HI catalase & $103 \pm 3.5$ & $58 \pm 3.2$ \\
\hline+ & - & - & - & + & - & NT & 100 \\
\hline+ & + & - & - & + & - & NT & $46 \pm 2.1$ \\
\hline \multirow[t]{2}{*}{+} & + & - & - & - & SOD + catalase & & \\
\hline & & & & & + mannitol & NT & $0^{n}$ \\
\hline+ & + & - & - & - & - & NT & $0^{n}$ \\
\hline+ & + & + & - & - & - & NT & $0^{\circ}$ \\
\hline+ & + & + & + & - & - & $103 \pm 2.8$ & $79 \pm 3.2$ \\
\hline
\end{tabular}

NT, not tested.

* Concentrations: PMN, $4 \times 10^{6} / \mathrm{ml} \mathrm{NaN}_{3}, 2 \mathrm{mM}$. The buffer was HBSSG, pH 7.8.

$\$$ The concentrations are the same as Table I. The buffer was HBSSG, pH 7.8.

$\$$ The results (mean of three experiments $\pm 1 \mathrm{SEM}$ ) are expressed as a percentage of $\mathrm{O}_{2}{ }^{-}$. detected under standard conditions (pretreated tubing, $4 \times 10^{6} \mathrm{PMN} / \mathrm{ml}$ ). $100 \%$ corresponds to 2.6 $\mathrm{nM}$ of $\mathrm{O}_{2}{ }^{\circ}$.

"The results (mean of three experiments \pm I SEM) are expressed as in Table I.

" Control for effects of all reagents used on the enzymatic activity of elastase (EIC $=0$ represents $100 \%$ elastolysis).

of incubation at $37^{\circ} \mathrm{C}, \mathrm{O}_{2}{ }^{-}$could be detected inside the dialysis bag (Table II). Enzymes released from the PMN were prevented from interacting with the contents of the bag by the dialysis membrane. As shown in Table II, the EIC of serum and of purified $\alpha_{1}$-Pi present inside of the bag was partly suppressed. The activity of elastase alone was unaffected (Table II). Untreated dialysis membranes (no immune-complex "coating" or antigencoating alone) did not stimulate PMN to produce these effects (Table II, line 4).

As is also shown in Table II, catalase, SOD, and mannitol (when present separately) partially protected serum elastase inhibitor from inactivation. When these agents were added together, no further increase in protection was observed (Table II), suggesting that other antiprotease-inactivating pathways may be functioning in the case of PMN. In view of the ability of leukocyte myeloperoxidase to generate a number of potent oxidants (13), PMN might be expected to also possess a myeloperoxidase-dependent pathway capable of inacti- vating $\alpha_{1}-\mathrm{Pi}$. To test this, $\mathrm{NaN}_{3}$ was added to the PMN suspension at a concentration sufficient to inhibit myeloperoxidase (13) without inhibiting $\mathrm{H}_{2} \mathrm{O}_{2}(13)$ or $\mathrm{O}_{2}$ ' production (13). As shown in Table II, $\mathrm{NaN}_{3}$ partially prevented serum inactivation by phagocytosing PMN. Combination of SOD, mannitol, and $\mathrm{NaN}_{3}$ resulted in almost complete protection of serum EIC $(92.6 \pm 0.8 \%$ of the control value).

Previous work has implicated oxidants released from PMN as tissue-damaging agents in inflammation because of oxidant cytotoxicity (14), oxidant-mediated degradation of structural polysaccharides (12), oxidantmediated bactericidal effects (15), and the reported antiinflammatory effects of SOD (16). Our results suggest that, at sites of inflammation, oxidants released from PMN could also act by altering the local balance between proteases and antiproteases, rendering adjacent tissue structures more susceptible to damage by enzymes simultaneously released from these cells. In this connection, it is important to note that the amount of 
$\mathrm{O}_{2}{ }^{-}$which could be detected in our P.MN suspensions was 30 times greater than that measured within the dialysis bags (data not shown). Extracellular fluids contain only traces of catalase and SOD (12), so that protease inhibitors in the microenvironment of phagocytically active PMN at sites of inflammation may be exposed to a much higher level of oxidants than was the case in the experiments described in this paper. Finally, mononuclear phagocytes (including alveolar macrophages) have also been shown to generate a number of potent oxidants (7). Therefore, oxidative inactivation of $\alpha_{1}-\mathrm{Pi}$ by these cells may contribute to connective tissue damage observed in chronic inflammatory processes, including lung diseases such as pulmonary emphysema.

\section{ACKNOWLEDGMENTS}

This work was supported by grant HL-14262 from the National Heart, Lung, and Blood Institute and by grant 1143 from the Council for Tobacco Research-U. S. A., Inc.

\section{REFERENCES}

1. Havemann, K., and A. Janoff. 1978. Neutral Proteases of Human Polymorphonuclear Leukocytes. Urban \& Schwarzenberg, Baltimore. 468 pp.

2. Janoff, A., and J. Scherer. 1968. Mediators of inflammation in leukocyte lysosomes. IX. Elastinolytic activity in granules of human polymorphonuclear leukocytes.J. Exp. Med. 128: 1137-1155.

3. Lazarus, G. S., R. S. Brown, J. R. Daniels, and H. M. Fullmer. 1968. Human granulocyte collagenase. Science (Wash. D. C.). 159: 1483-1485.

4. Henson, P. M. 1971. The immunologic release of constituents from neutrophil leukocytes. I. The role of antibody and complement on non-phagocytosable surfaces or phagocytosable particles. J. Immunol. 107: 15:35-1546.

5. Ohlsson, K. 1978. Interaction of granulocyte neutral proteases with alpha $a_{1}$-antitrypsin, alpha $a_{2}$-macroglobulin and alpha ${ }_{1}$-antichymotrypsin. In Neutral Proteases of Human Polymorphonuclear Leukocytes. K. Havemann and A. Janoff, editors. Urban \& Schwarzenberg, Baltimore. $167-177$.
6. Carp, H., and A. Janoff. 1978. Possible mechanisms of emphysema in smokers. In vitro suppression of serum elastase-inhibitory capacity by fresh cigarette smoke and its prevention by antioxidants. Am. Rev. Respir. Dis. 118: $617-621$.

7. Weiss, S. J., P. K. Rustage, and A. F. LoBuglio. 1978. Human granulocyte generation of hydroxyl radical.J. Exp. Med. 147: 316-323.

8. Blondin, J., and A. Janoff. 1976. The role of lysosomal elastase in the digestion of Escherichia coli proteins by human polymorphonuclear leukocytes. Experiments with living leukocytes. J. Clin. Invest. 58: 971-979.

9. McCord, J. M., and I. Fridovich. 1969. Superoxide dismutase. An enzymic function for erythrocuprein (hemocuprein). J. Biol. Chem. 244: 6049-6055.

10. Beers, R. F., Jr., and I. W. Sizer. 1952. A spectrophotometric method for measuring the breakdown of hydrogen peroxide by catalase. J. Biol. Chem. 195: 133-140.

11. McCord, J. M., and E. D. Day. 1978. Superoxide dependent production of hydroxyl radical catalyzed by ironEDTA complexes. FEBS (Fed. Eur. Biochem. Soc.) Lett. 86: $139-142$.

12. McCord, J. M. 1974. Free radicals and inflammation: protection of synovial fluid by superoxide dismutase. Science (Wash. D. C.). 185: 529-531.

13. Roos, D., M. L. J. van Schaik, R. S. Weening, and R. Wever. 1977. Superoxide generation in relation to other oxidative reactions in human polymorphonuclear leukocytes. In Superoxide and Superoxide Dismutases. A. M. Michelson, J. M. McCord, and I. Fridovich, editors. Academic Press, Inc., New York. 307-316.

14. Salin, M. L., and J. M. McCord. 1975. Free radicals and inflammation. Protection of phagocytosing leukocytes by superoxide dismutase. J. Clin. Invest. 56: 1319-1322.

15. Johnston, R. B., B. B. Keele, Jr., H. P. Misra, J. E. Lehmeyer, L. S. Webb, R. L. Baehner, and K. V. Rajogopalan. 1975. The role of superoxide anion generation in phagocytic bactericidal activity. Studies with normal and chronic granulomatous disease leukocytes. J. Clin. Invest. 55: $1357-1372$.

16. Menander-Huber, K. B., and W. Huber. 1977. Orgotein, the drug version of bovine $\mathrm{Cu}-\mathrm{Zn}$ superoxide dismutase II. A summary account of clinical trials in man and animals. In Superoxide and Superoxide Dismutases. A. M. Michelson, J. M. McCord, and I. Fridovich, editors. Academic Press, Inc., New York. 537-549. 